Universidad de Lima

Facultad de Comunicación

Carrera de Comunicación

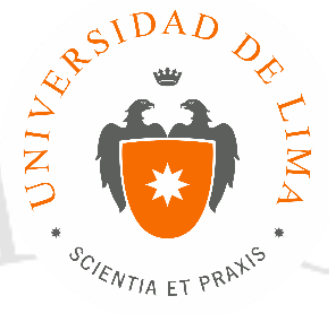

\title{
CAMPAÑA DE LANZAMIENTO DE
}

\section{CERVEZA SIN ALCOHOL SCHWELLER EN}

\section{EL MERCADO PERUANO}

Trabajo de Suficiencia Profesional para optar el Título Profesional de Licenciado en

Comunicación

\section{Ivana Tryon Maldonado}

Código 20121297

$$
\begin{gathered}
\text { Lima - Perú } \\
2018
\end{gathered}
$$




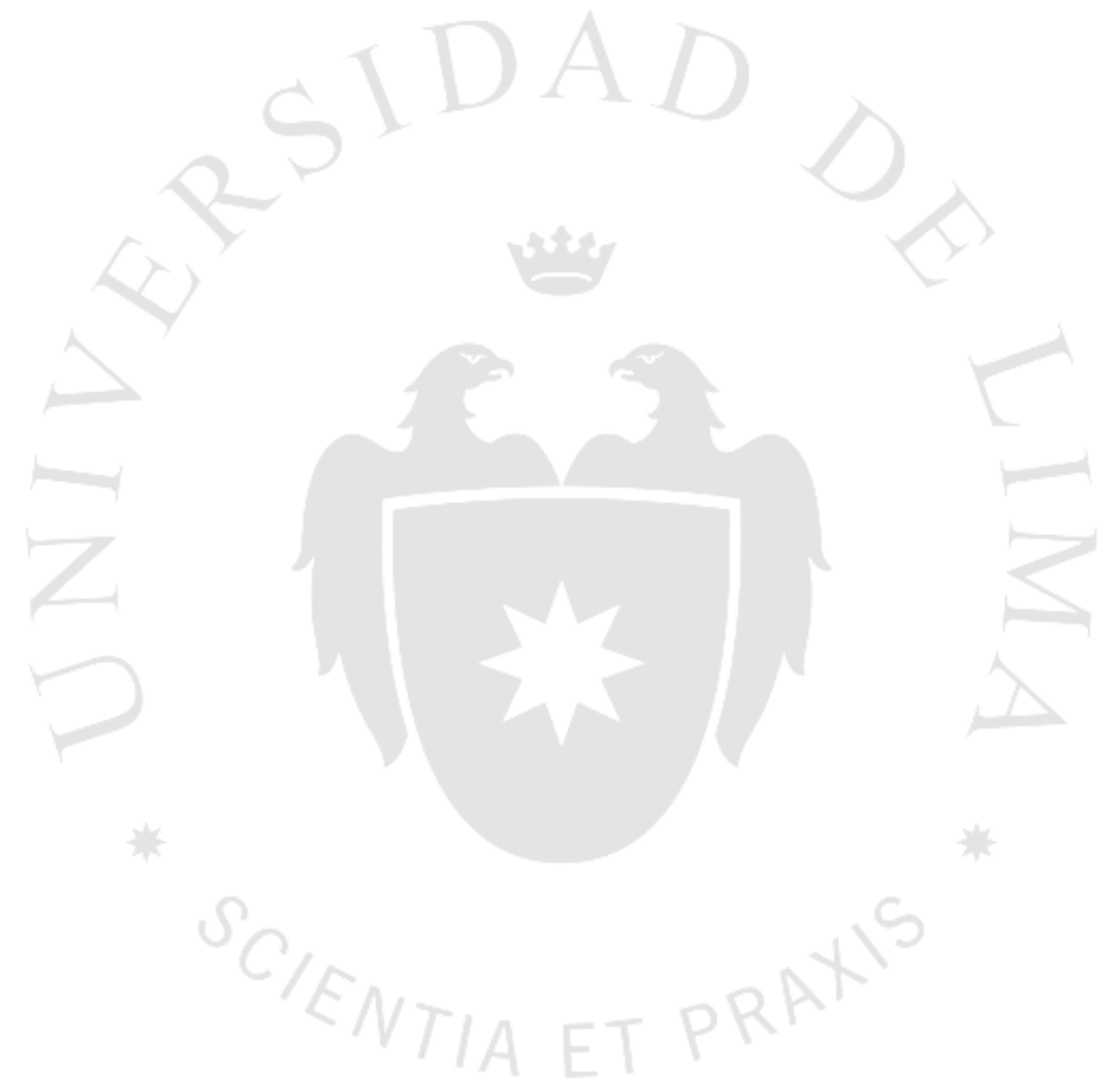




\section{CAMPAÑA DE LANZAMIENTO DE \\ CERVEZA SIN ALCOHOL SCHWELLER EN \\ EL MERCADO PERUANO}




\section{ÍNDICE}

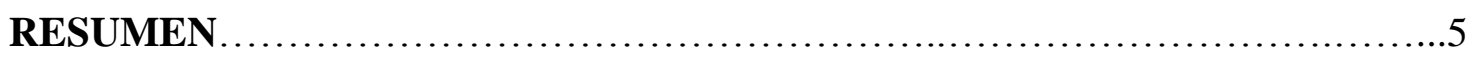

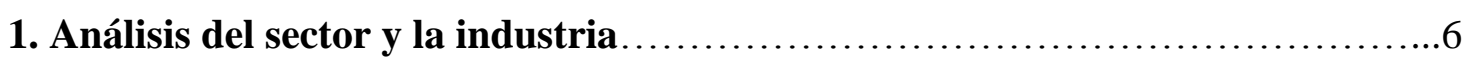

2. El producto y la marca ........................................................

3.1 Características.................................................... 7

3.2 Mercado objetivo.................................................

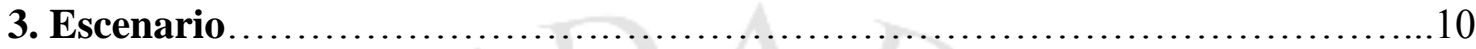

3.1 Análisis FODA...............................................11

3.1 Análisis de la competencia.......................................12

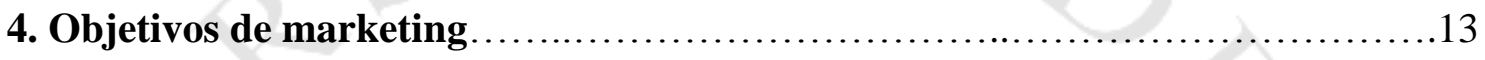

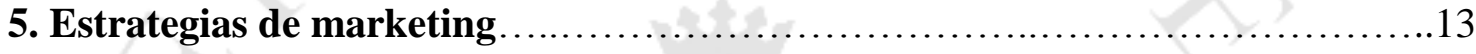

5.1 Producto............................................................

5.2 Precio..............................................................

5.3 Plaza o distribución.................................................... 15

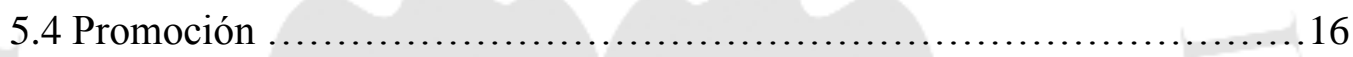

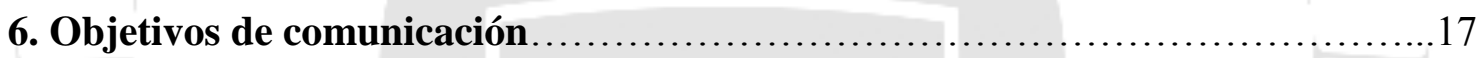

7. Estrategias de comunicación......................................... 17

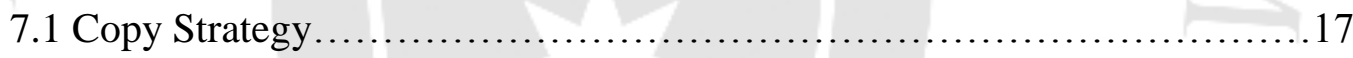

7.2 Estrategia creativa...............................................18

7.3 Estrategias de medios........................................... 19

7.3.1 ATL.............................................................20

7.3.2 Medios Digitales...............................................21

7.3.3 Relaciones Públicas.............................................23

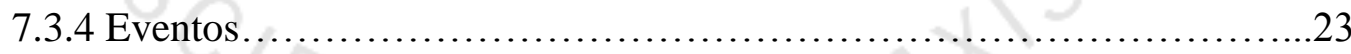

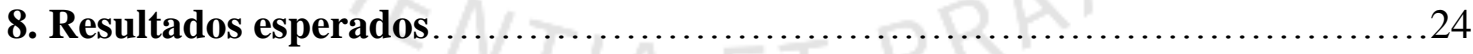

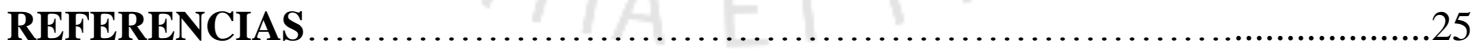

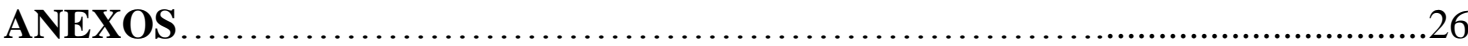




\section{RESUMEN}

En el presente informe se evaluará el análisis de una importante cervecería transnacional que incursionará en el mercado peruano con una cerveza sin alcohol, con sabor similar al de la cerveza tipo "lager".

En este análisis se propone un cambio de imagen y nombre de la marca, así como también la propuesta estratégica y creativa para ser bien recibida en el público objetivo y lograr cumplir con los objetivos de marketing y comunicación propuestos por el cliente.

Una de las estrategias utilizadas es dividir la campaña de tres meses en dos etapas: una de intriga de 2 semanas y la otra de lanzamiento de 11 semanas, para lograr una respuesta positiva que llame la atención de dicho target a través de los medios que más usa.

Se encontró un nicho en el mercado peruano de personas que no siempre toman bebidas alcohólicas en reuniones sociales, pero no quieren ser excluidas solo porque no están tomando. Schweller entra en el mercado para satisfacer las necesidades de estos posibles clientes. 


\section{ANÁLISIS DEL SECTOR Y LA INDUSTRIA}

La cerveza, según el INEI, es la bebida alcohólica más consumida en los hogares peruanos. El consumo per cápita es de 45.4 litros por persona al año, según un estudio reciente de Euromonitor.

En la industria cervecera peruana, Unión de Cervecerías Peruanas Backus y Johnson tiene el liderazgo con $99 \%$ de participación en el mercado, según The Top 10.000 Companies 2017, dejando el $1 \%$ restante al mercado artesanal.

El año pasado, según un estudio del Banco Central de Reserva (BCR), el consumo de cerveza aumentó en Perú en un 9.1\% a diferencia del 2016. Según Monitor, la inversión en medios ha crecido en $3 \%$ en lo que va del 2018 en comparación con el año pasado, debido al mundial de fútbol, porque son los meses previos y durante donde hubo más inversión y, por lo tanto, consumo, especialmente para la marca Cristal, la cual patrocina la selección peruana. Las marcas que le siguen son Pilsen, Tres Cruces, Cusqueña, Budweiser, Heineken, coincidiendo con las favoritas del target según un estudio de Target Group Index de Ibope (TGI).

Cervezas: inversión mediática ene-ago 2018

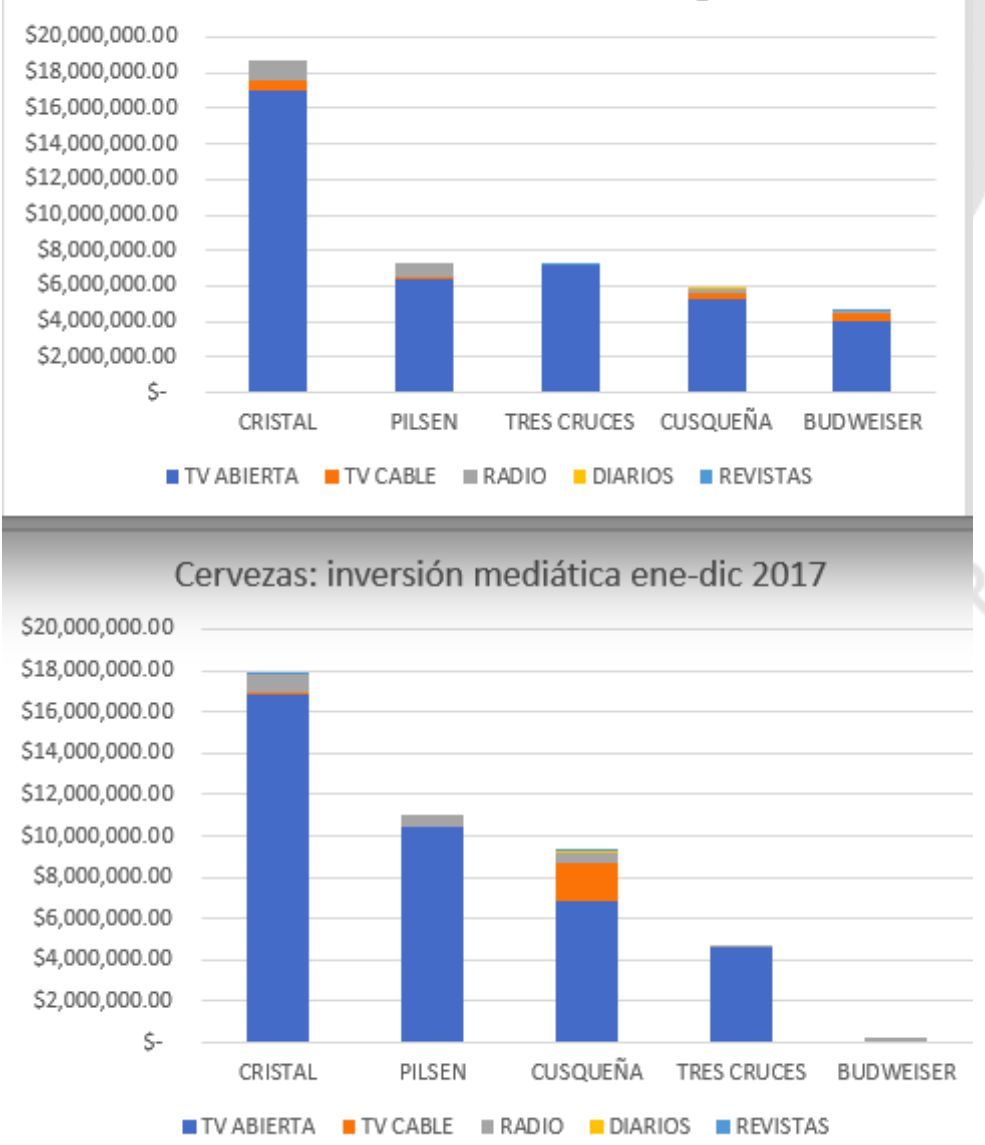


Como se puede ver en el cuadro, estas marcas invierten principalmente en televisión abierta, seguido por cable, radio y por último diarios y revistas.

En el Perú, encontramos en el mercado cervecero distintos tipos de cervezas entre las que podemos encontrar: Lager, Ale, de trigo, Porter \& Stout, Lambic, Artesanal, 0\% alcohol, entre las más conocidas.

Actualmente, no hay inversión publicitaria en Perú sobre cervezas sin alcohol, por lo que resulta ventajoso para la marca a desarrollar puesto que los esfuerzos de marketing van a estar centrados en lograr el conocimiento y recordación de marca frente a su competencia. Sin embargo, también hay obstáculos, al ser nueva en el mercado y estar dirigida a un público que acostumbra a tomar mucha cerveza pero con alcohol.

\section{EL PRODUCTO Y LA MARCA}

El producto es una cerveza alemana tipo lager con color amarillo dorado y un rico sabor con 3 puntos de 5 de amargo y 3 puntos de 5 de dulce. El porcentaje de alcohol es de $0.00 \%$, en comparación con las cervezas libres de alcohol de la competencia, las cuales tienen $0.05 \%$, dándole a la marca una ventaja diferencial.

\subsection{Características}

\section{Nombre}

La palabra "schwelle" en alemán significa "umbral", la cual tiene relación con el concepto creativo que se explicará más adelante. Se refiere a ese escenario en donde todos en la reunión están tomando menos uno. A esa persona la ven como "el aburrido" como si no fuera parte de la fiesta. Para que no ocurra esto, esa persona tiene que cruzar un umbral imaginario tomando una Schweller para formar parte de la diversión. Se puso la letra "r" al final de la palabra para darle un aspecto más formal.

\section{$\underline{\log 0}$}

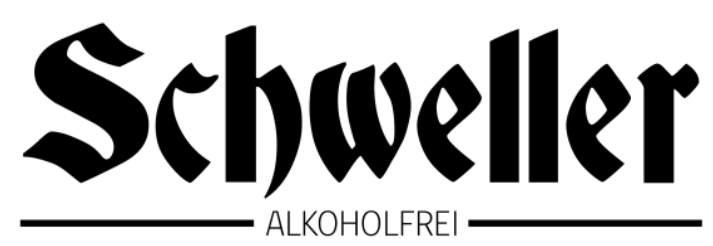

Se pasó por todo un proceso creativo al crear el logo para llegar a la decisión final. Se utilizó la fuente Deustch Gothic para darle un efecto más alemán. 
Se decidió poner "ALKOHOLFREI" debajo del nombre en vez de $0 \%$ alcohol porque este último se veía más informal y no iba con la línea alemana que se le quería dar al producto. Además es una palabra en alemán que se entiende y tiene una traducción literal en español.

Los colores elegidos para la marca son:

-Amarillo/dorado siendo el color de la cerveza en sí para comunicar energía, diversión y espontaneidad.

-Azul como color de fondo para transmitir libertad y verdad, pero a la vez seriedad y confianza.

-Blanco para el color de las letras para que resalte sobre el fondo y comunicar pureza, relacionándolo con que es una bebida no alcohólica.

\section{Presentaciones}

(Ver PDF adjunto - Schweller Packaging)

Se diseñó el packaging para la botella de $310 \mathrm{ml}$ y la lata de $355 \mathrm{ml}$ con los colores propuestos en el punto anterior. Además, se agregaron los siguientes isotipos:

-Brandenburger tor: es la puerta de Brandenburgo de Berlín modificada para la marca. También se puede visualizar (a una opacidad más baja) unos rectángulos sobre el fondo azul en forma de ladrillos separados. Se eligió poner estos elementos para seguir en relación con la metáfora del umbral que se quiere llegar a comunicar.

-Siegessäule: la Columna de la Victoria que se encuentra en el Tiergarten en Berlín, la cual es retratada como un ángel, dándole el valor de seguridad a la marca.

\section{$\underline{\text { Marca }}$}

Atributos: tiene el mismo sabor al de una cerveza de tipo lager.

Beneficios: como beneficio funcional es que tiene $0 \%$ de alcohol y sirve para no emborracharse pasándola bien. El beneficio emocional va ligado a la diversión y la amistad. Por último, como beneficio de autoexpresión la gente se siente que pertenece.

Valores centrales: seguridad, calidad, amistad.

Valores secundarios: sociabilidad, autenticidad.

\subsection{Mercado objetivo}

Si bien el producto está dirigido a los adultos jóvenes; es decir, hombres y mujeres de 18 a 35 años, de NSE AB, la estrategia está enfocada principalmente en el nicho de personas de este segmento que no toman o no pueden tomar bebidas alcohólicas. Según un estudio de TGI 2017, el 36\% de este target no consume cerveza. 


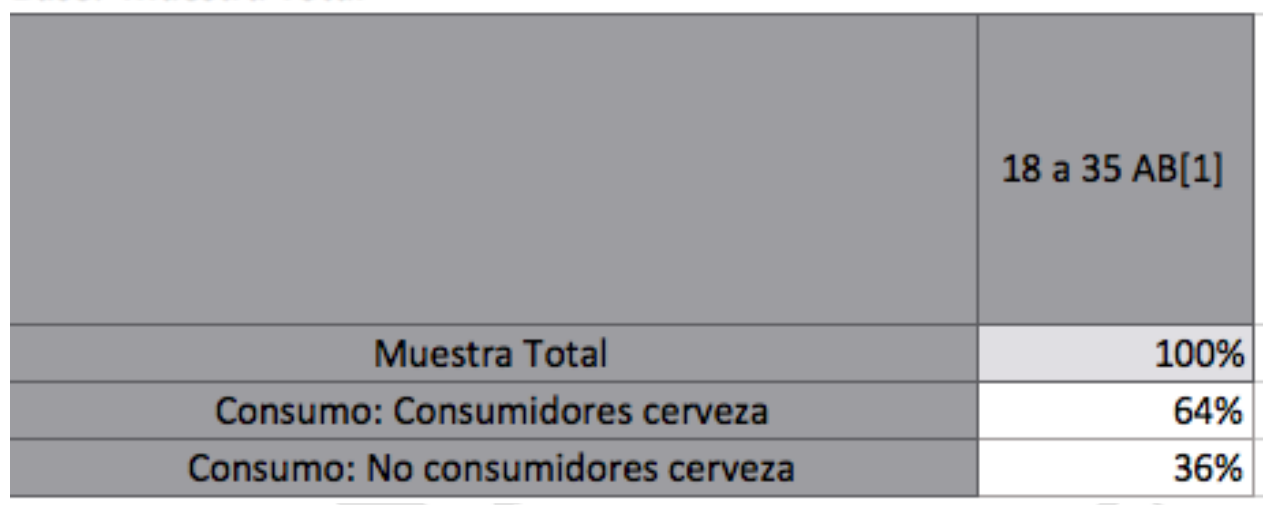

Son sofisticados, modernos, cosmopolitas y se preocupan mucho por la imagen personal. Son cazadores de tendencias. Les importa mucho su estatus. Siguen la moda. Según el estudio del Perfil del adulto joven 2018 de Ipsos, las actividades que este target realiza para divertirse son ver algún programa en la televisión o conectarse a las redes sociales (en casa); y salir a comer, hacer ejercicio, ir al cine o ir a casa de amigos (fuera de casa).

Se hizo una encuesta al público objetivo preguntando qué bebida alcohólica prefieren y la mayoría respondió cerveza con $28.3 \%$, seguidas de pisco con $25 \%$, ron con $18.3 \%$, entre otras. También se les preguntó en qué situaciones toman y el $88.3 \%$ respondió en reuniones, lo cual coincide con la información de Ipsos acerca de actividades para divertirse.

En un estudio que se sacó de la plataforma TGI 2017, se le preguntó al target si la razón de tomar alcohol es para emborracharse y solo el $24 \%$ respondió que sí. Esta información es útil para esta campaña puesto que hay un gran porcentaje que dice lo contrario y al ser un producto sin alcohol puede ser bien recibido por aquellas personas que dijeron que no. Además, en este mismo estudio, el $42 \%$ respondió que les gusta probar nuevos tragos y bebidas, por tal motivo la comunicación debe ser clara y directa a ellos para lograr aceptación, recordación y finalmente recomendación.

Volviendo a la encuesta, se les preguntó qué bebida tomaban cuando no podían o no querían tomar alcohol, siendo agua, gaseosa y jugo las mejores opciones; y si les interesaría una cerveza sin alcohol para situaciones como esas, el 45\% respondió que sí, $31.7 \%$ que tal vez y $23.3 \%$ que no. Se esperaban respuestas como la de estos últimos, porque normalmente a los jóvenes les gusta el alcohol y creen que una cerveza sin alcohol no tiene el mismo sabor y si lo tiene, prefieren tomar otras bebidas o 
simplemente no les atrae. Sin embargo, a los que respondieron sí o tal vez se pueden resaltar las siguientes respuestas: "es una buena solución para cuando no se pueda tomar como cuando hay que manejar o estar con antibióticos", "quiero cuidar mi salud" y piensan que este producto es más saludable o "quiero sentirme parte de la reunión y al tomar un cerveza así no tenga alcohol igual me voy a divertir”.

Bajo este último insight se va a basar la campaña: las personas prefieren tomar para sentirse incluidas en situaciones sociales, con este producto pueden "engañar" a sus amigos, poder tomar sin preocuparse de que los vayan a excluir, de manejar o de no pasarla bien. Porque tomando Schweller y por efecto placebo la pasarían bien así no estén tomando alcohol.

\section{ESCENARIO}

Como se mencionó anteriormente, Backus tiene el 99\% de participación en la industria cervecera, el otro $1 \%$ lo tienen las pequeñas marcas artesanales. Actualmente, las cervezas sin alcohol no son conocidas en el mercado peruano puesto que no se invierte en publicidad. Sin embargo, se pueden encontrar cervezas sin alcohol como Erdinger Alkohol Frei y Bitburger en supermercados como Wong, Plaza Vea y Vivanda. Uno de los insights aterrizados fue que las personas no tomaban cuando van en carro a una reunión. Con respecto a eso, en Perú, manejar en estado de ebriedad es una falta muy grave según el Reglamento Nacional de Tránsito, e incluso es considerado un delito en el Código Penal. El grado alcohólico máximo permitido a los conductores que sean intervenidos por la autoridad se establece en 0,50 gramos de alcohol por litro de sangre (D. S. N. ${ }^{\circ}$ 016-2009-MTC, art. 307), lo cual equivale al consumo de 3 vasos de cerveza o a 2 copas de vino.

Se está al tanto de casos como el de Quara, que quiso abrir un nuevo nicho y dinamizar el consumo de cerveza pero por su controversial publicidad la propuesta no convenció (Mercado Negro, 2014). Los consumidores vieron que esta publicidad denigraba a la mujer; asumieron que por ser mujer no podían tomar las cervezas comunes. En estas épocas, la lucha por la igualdad ya tiene mayor forma y respaldo, por lo que hay que tener cuidado con lo que se comunique. Para este caso, el nicho encontrado son aquellas personas a las que les gusta salir y sentirse parte de la reunión y así no estén tomando, tienen "todas las vibras" para divertirse. Esas vibras las pondría Schweller. 


\subsection{Análisis FODA}

\section{Fortalezas}

- Es una marca alemana y a este público le interesa saber de otras culturas.

- Contiene 0\% alcohol.

- Tiene un precio adquirible de S/. 5.50.

- Es de buena calidad.

- Se puede encontrar fácilmente en supermercados y minimarkets.

\section{Debilidades}

- Es nueva y desconocida.

- No tiene comunicación de marca.

\section{Oportunidades}

- El mercado de cervezas sin alcohol está poco explorado.

- Fuerte poder adquisitivo del mercado meta.

- Les gusta probar nuevos tragos.

- Existe un nicho que no toma.

\section{$\underline{\text { Amenazas }}$}

- La competencia va varios años en el mercado.

- Aguas, gaseosas y jugos también son parte de la competencia.

\begin{tabular}{|l|l|}
\hline Estrategias -FO & Estrategias -FA \\
\hline -Aprovechar que es una marca extranjera & -Comunicar que tiene 0,00\% alcohol en \\
para que llame la atención del target y la & comparación de las otras que dicen ser \\
prueben por ser diferente. & libre de alcohol pero tienen $0,05 \%$. \\
-Comunicar que es una bebida no & -Hacer alianzas con los supermercados \\
alcohólica porque, al no haber & para poner publicidad en el punto de \\
comunicación de otra marca, la van a & venta. \\
asociar con la nuestra. & -Hacer alianzas con bares y discotecas \\
-Mantener el precio referencial por el & para estar más cerca cuando el público \\
cliente, siendo este el más bajo del rubro & busque la marca. \\
y los consumidores puedan comprar el & \\
producto individual y el six pack. & \\
\hline
\end{tabular}




\begin{tabular}{|l|l|}
\hline Estrategias -DO & Estrategias -DA \\
\hline -Crear un nombre que pegue y que llame & -Dar a conocer que es el mismo sabor a \\
la atención. & cerveza. \\
-Creatividad al hacer el packaging & -Hacer que el público se sienta incluido \\
-Ligarlo al deporte, la salud, la seguridad & en una reunión con esta cerveza. \\
(cuando manejan). & -Dar la información que los \\
-Aprovechar los medios propios para & consumidores buscan. \\
llegar al público. & \\
\hline
\end{tabular}

\subsection{Análisis de la competencia}

\section{Erdinger}

Erdinger Weissbräu es una marca de cerveza con varias líneas de producto. Alkoholfrei es una de ellas y, como su mismo nombre lo dice, no tiene alcohol. En realidad tiene 0.05\%. Es la líder en el mercado de cervezas sin alcohol, pero no se refieren a sí mismos como cerveza sino como "isotónica".

Su comunicación de marca se enfoca en lo saludable y siempre auspicia a deportistas y eventos deportivos.

Aprovechan sus medios propios como redes sociales y página web, en donde escriben constantemente (y en inglés a pesar de ser una cerveza alemana) para llegar a un público más internacional.

El slogan de la marca es "Quench your thirst" u otras veces "Thirst quenchers" lo cual significa “quitar la sed”. Relacionándolo con el deporte, las personas llegan cansadas de jugar, entrenar o competir y necesitan calmar su sed tomando una Erdinger.

Su presentación de $330 \mathrm{ml}$ tiene un precio de S/.9.50, siendo la más costosa en Perú.

\section{Bitburger}

Es una cerveza alemana y, en comparación con la anterior, esta tiene todo su contenido y comunicación de marca en alemán. Mientras que Erdinger es más conocida internacionalmente, esta se concentra más en Alemania.

Por otro lado, tienen varias similitudes como por ejemplo: se autodenomina "isotónica y vitamínica" en vez de cerveza; su porcentaje de alcohol es $0.05 \%$ y su público también son los deportistas, puesto que auspiciaron el partido Alemania - Perú el domingo 09 de setiembre. 
El slogan de la marca es "Bitte eim bit" que quiere decir "Por favor un poco", dándole un sentido exquisito como si fueran los mismos consumidores los que la piden.

Tiene 3 sabores distintos y su presentación de $330 \mathrm{ml}$ la venden en Perú a un precio de S/.6.00.

\section{OBJETIVOS DE MARKETING}

Los objetivos específicos de marketing que la empresa se planteó fueron los siguientes:

- Generar conocimiento y recordación de marca por parte del target objetivo en el lapso de 6 meses.

- Alcanzar el liderazgo en el rubro bebidas sin alcohol, en el mercado peruano en el lapso de un año.

\section{ESTRATEGIAS DE MARKETING}

Con el propósito de alcanzar los objetivos propuestos, se implementarán las siguientes estrategias.

\subsection{Producto}

Si bien ya existe el producto de cervezas sin alcohol (cuando en realidad tienen $0.05 \%$ ) en Perú, este es un nuevo producto porque como mencioné anteriormente tiene la ventaja diferencial al ser $0.00 \%$ alcohol. Además, a pesar de que la marca recién está entrando en el mercado peruano, no significa que vaya a nuevos mercados. En realidad, va a aquellas personas que les gusta tomar cerveza pero que por distintas situaciones y circunstancias no pueden. Según la matriz de Ansoff, se trataría de una estrategia de producto.

\begin{tabular}{|c|c|c|}
\hline & Productos actuales & Productos nuevos \\
\hline Mercados actuales & $\begin{array}{c}\text { Penetración en el } \\
\text { mercado }\end{array}$ & $\begin{array}{c}\text { Desarrollo de } \\
\text { productos }\end{array}$ \\
\hline Mercados nuevos & $\begin{array}{c}\text { Desarrollo en el } \\
\text { mercado }\end{array}$ & Diversificación \\
\hline
\end{tabular}


Tratándose de una nueva cerveza, se debe desarrollar el producto resaltando sus beneficios funcionales, emotivos y de autoexpresión acompañados de un buen concepto creativo para el que el público objetivo se sienta identificado.

Aparte de la presentación de la botella de $310 \mathrm{ml}$ y la lata de $355 \mathrm{ml}$ (cada una con su six pack), se piensa hacer merchandising de la marca como vasos o schops de cerveza coleccionables.

\subsection{Precio}

Schweller se encuentra en la etapa de introducción. Es por eso que debe ser lanzado con un precio bajo en la categoría. Al ser un producto nuevo, el objetivo de esta estrategia es lograr una penetración rápida en el mercado y frenar el crecimiento de la competencia. El promedio en las cervezas sin alcohol (de $330 \mathrm{ml}$ ) es S/.7.80. Schweller, al tener un precio más bajo, pone al producto en una posición favorable en el mercado. Se estaría atacando a la competencia mediante una estrategia de flanqueo; es decir, por sus debilidades.

De la encuesta al público objetivo se puede apreciar que la mayoría puso que pagaría de S/.2.00 a S/.4.50 por el producto; sin embargo, entre las respuestas en rojo y amarillo, hay otra mayoría: los que pagarían de S/.5.00 a S/.10.50.

\section{¿Cuánto pagarías por una botella de $310 \mathrm{ml}$ de cerveza sin alcohol?}

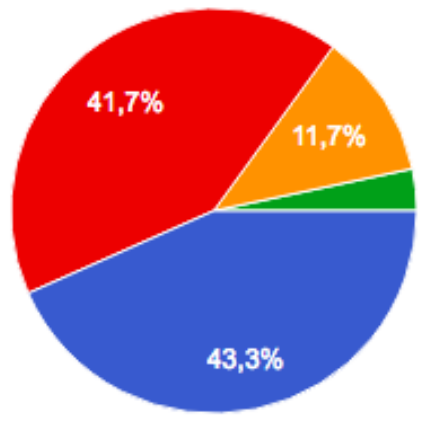

$\mathrm{S} / .2 .00-\mathrm{S} / 4.50$

$\mathrm{S} / .5 .00-\mathrm{S} / .7 .50$

$\mathrm{S} / .8 .00-\mathrm{S} / .10 .50$

$\mathrm{S} / .11 .00-\mathrm{S} / .13 .50$

Los consumidores hoy en día hacen el proceso de compra muy informados, comparando el beneficio versus costo. Como se puede ver en la encuesta, ellos prefieren los productos con precios bajos o que están en promoción; sin embargo, no se quiere llegar al punto en el que no vean el valor y la calidad. Por tal motivo, el precio se mantiene con S/.5.50 para la botella de $310 \mathrm{ml}$ y S/.6.50 para la lata de $355 \mathrm{ml}$, para que 
llame la atención de los posibles clientes, generen la compra, prueben el producto y finalmente, lo recomienden.

\subsection{Plaza}

Con este producto, se quiere llegar a nivel nacional. En la etapa de lanzamiento, se utilizará la estrategia push, la cual empuja el producto hacia el consumidor final. Para ello, se necesitan alianzas estratégicas con los principales supermercados y minimarkets de Lima y provincias para que promuevan el producto en el punto de venta. Por ejemplo:

- Ubicar preferentemente el producto, en lugares donde aumentan las posibilidades de ser adquirido por el consumidor, como en las cabeceras de góndola, los estantes a la altura de los ojos y las zonas cercanas a las cajas.

- Poner mensajes alrededor: afiches, flechas o flyers que cuelguen del stand o estén pegados a las paredes o suelo del establecimiento para dirigir el tráfico y la atención de los consumidores.

- Permitir acumular puntos por la compra del producto.

- Sampling: tener un impulsador que de a probar gratis el producto para demostrar el rico (y mismo) sabor de cerveza.

También cabe la posibilidad de tener alianzas con bares, discotecas y restaurantes. Según la encuesta realizada al público objetivo, estos lugares ocupan un gran porcentaje en donde el target desea encontrar el producto.

\section{¿En dónde te gustaría encontrar este producto?}

\section{0 respuestas}

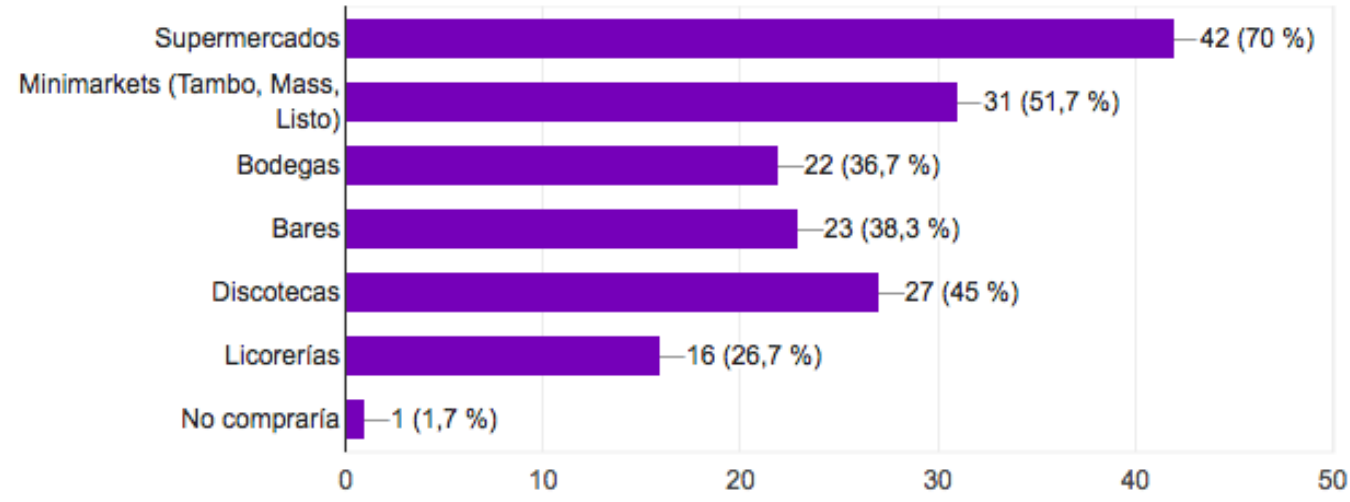


Esto se puede llegar a concretar en la etapa de mantenimiento y después de los primeros 6 meses para lograr el segundo objetivo de marketing con una estrategia pull; es decir, que sean ahora los consumidores los que van hacia el producto.

\subsection{Promoción}

Mediante la promoción se quiere llegar a influenciar a los clientes sobre hechos - por ejemplo las actitudes en una reunión cuando hay y no hay cerveza - y emociones divertirse sin alcohol, sin preocupaciones.

Los medios en los que se invertiría más en la promoción del producto son vía pública y televisión por cable, los cuales causan más impacto en la audiencia como se va a explicar más adelante.

Es importante también, tener presencia en redes sociales y contar con una página web. Según el estudio del Perfil del usuario de redes sociales 2018 de Ipsos, 1 de cada 10 usuarios de redes sociales afirma seguir marcas (15\%) y la cuarta parte afirma que una marca ha influenciado su compra de alguna manera (32\%). Además, el 55\% recomiendan marcas en redes sociales. Por tal motivo, hay que estar activos y estar en constante comunicación directa con el consumidor para recibir feedback y evaluar si el producto está siendo aprobado. Lograr una comunicación de word of mouth positiva de la marca entre los propios consumidores es una de las metas más importantes puesto que es más creíble.

Se hará uso de las relaciones públicas principalmente para ayudar construir la marca en la etapa de lanzamiento.

Como se mencionó anteriormente, se pretende hacer schops como parte del merchandising, se puede hacer una promoción de ventas para que se lleven el schop por la compra de 2 six packs, después de la etapa de lanzamiento para lograr más ventas a corto plazo.

Entrar al mercado mediante un evento es preciso para esta campaña. En la etapa de intriga se puede ayudar a promocionar este mismo para tener un contacto más directo con el público objetivo y llegar a causar tal impacto que siga resonando en redes sociales después del día del lanzamiento, para luego pasar a la siguiente etapa y ser más masivo por un periodo de 3 meses en total. 


\section{OBJETIVOS DE COMUNICACIÓN}

Los objetivos específicos de comunicación que la empresa se planteó fueron los siguientes:

- Informar sobre el lanzamiento de Schweller, destacando su agradable sabor y que no contiene alcohol.

- Informar sobre los puntos de venta de la marca.

\section{ESTRATEGIAS DE COMUNICACIÓN}

\subsection{Copy Strategy}

En la estrategia comunicacional se trabajó sobre el insight: "Cuando en una reunión no puedo tomar, me siento excluido. Quiero sentirme parte de la reunión”.

Adicionalmente, algunas percepciones importantes de los adultos jóvenes que se consideraron en la campaña:

- "Solo el 24\% de los adultos jóvenes toman para emborracharse" (Kantar IBOPE Media , 2017). Esto quiere decir que el otro $76 \%$ solo toma para pasarla bien un rato y es ahí donde se quiere llegar: no hay necesidad de tomar alcohol para divertirse.

- "Fingir estar tomando sin llegar a embriagarse" (respuesta de encuesta). Con esto se puede jugar con el efecto placebo; es decir, uno cree que está tomando alcohol y por eso se comporta como si estuviese con los efectos del alcohol, cuando en realidad no llega a estar ebrio así tome grandes cantidades de este producto.

- "Cuido mi salud" (respuesta de encuesta). Muchos lo ven por el lado saludable, otros son deportistas y, mientras no embote como una cerveza normal, lo pueden consumir.

Por lo tanto, los elementos de la estrategia son los siguientes:

Concepto: No te quedes al otro lado de la fiesta, disfruta sin preocupaciones.

Promesa básica: Diviértete como si estuvieras tomando.

Soporte a la promesa: Mismo sabor de cerveza, $0 \%$ alcohol.

Tono de comunicación: Coloquial, alegre. 
Elementos obligatorios: Apelar al lado emocional de sentido de pertenencia pero explicando lo racional al decir que es una bebida sin alcohol.

Posicionamiento deseado: Schweller es la rica cerveza que no contiene alcohol que el joven peruano estaba esperando para disfrutar sin preocupaciones.

\subsection{Estrategia creativa}

La campaña publicitaria se dividió en dos fases:

- Etapa de intriga, con duración de 2 semanas en las cuales se realizarán acciones en vía pública, internet y radio con mensajes relacionados al efecto placebo.

- Etapa de lanzamiento. El develamiento de la marca será a través de un evento en el que participen influencers, líderes de opinión y el mismo público objetivo. El resto de la campaña tendrá una duración de 11 semanas. En esta etapa el video de 30 segundos es lo más importante.

\section{Cuña radial 20" (intriga)}

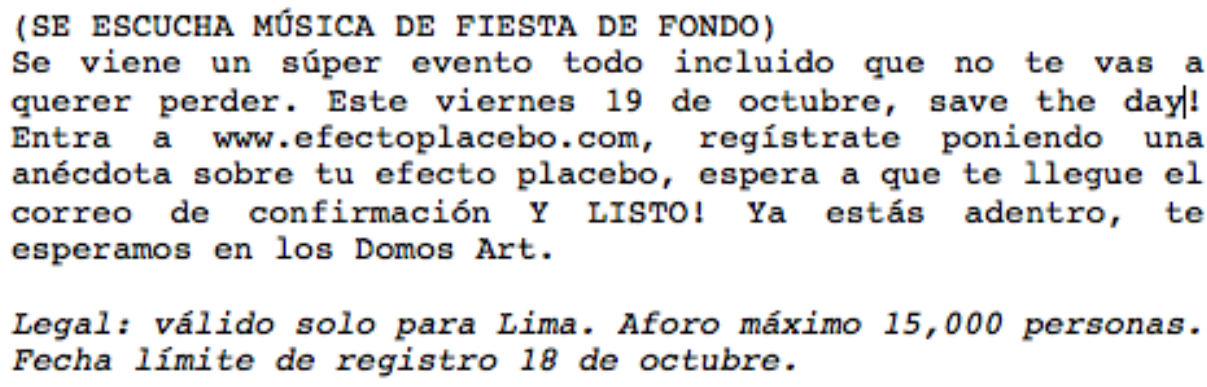

\section{TV Spot de 30" (lanzamiento)}

(Ver animatic adjunto - Schweller TV Spot) 
ESC. 1. CASA DE DIEGO. NOCHE

En una reunión por el cumpleaños de Diego se ve a un grupo alegre jugando beer pong. Natalia está mirando de lejos, con su celular en la mano. Se le acerca Carlos con una botella de Schweller en la mano.

\section{CARLOS}

Naty qué tal? Por qué no estás tomando?

NATALIA

Pucha porque estoy en carro.

CARLOS

(RIÉNDOSE)

Yo también! Por eso estoy tomando Schweller, la nueva cerveza sin alcohol. Quieres probarla?

NATALIA (SOPRENDIDA)

En serio? A ver? (PRUEBA LA CERVEZA)

Mmm está buena!

Carlos le invita una botella y se quedan hablando, tomando y riendo.

VOZ EN OFF

No te quedes al otro lado de la fiesta, únete con Schweller $y$ disfruta sin preocupaciones

Pack shot de la cerveza mientras juegan beer pong al fondo.

\subsection{Estrategia de medios}

Para llegar a los objetivos propuestos por la empresa, se tomó en cuenta los medios que los adultos jóvenes usan normalmente. Según Ipsos, la mayor parte de este target es digital; el $88 \%$ se conecta a internet todos los días y el $40 \%$ le ha dado clic alguna vez a un anuncio publicitario.

En el siguiente cuadro se puede apreciar la distribución del presupuesto con el total en dólares de los medios elegidos.

\begin{tabular}{|l|c|c|c|c|c|}
\hline & $\begin{array}{c}\text { Inversión sin } \\
\text { IGV }\end{array}$ & IGV 18\% & $\begin{array}{c}\text { Fee Agencia } \\
\text { 15\% }\end{array}$ & $\begin{array}{c}\text { IGV de } \\
\text { Agencia }\end{array}$ & TOTAL \\
\hline ATL & $\$ 205,585.02$ & $\$ 37,005.30$ & $\$ 30,837.75$ & $\$ 5,550.80$ & $\$ \mathbf{2 7 8 , 9 7 8 . 8 7}$ \\
\hline Digital & $\$ 53,000.00$ & $\$ 9,540.00$ & $\$ 7,950.00$ & $\$ 1,431.00$ & $\$ 71,921.00$ \\
\hline $\begin{array}{l}\text { Evento de } \\
\text { lanzamiento }\end{array}$ & $\$ 20,000.00$ & $\$ 3,600.00$ & $\$ 3,000.00$ & $\$ 540.00$ & $\$ 27,140.00$ \\
\hline PR & $\$ 9,000.00$ & $\$ 1,620.00$ & $\$ 1,350.00$ & $\$ 243.00$ & $\$ 12,213.00$ \\
\hline $\begin{array}{l}\text { Producción y } \\
\text { Realización }\end{array}$ & $\$ 44,023.50$ & $\$ 7,924.23$ & $\$ 6,603.53$ & $\$ 1,188.63$ & $\$ 59,739.89$ \\
\hline \multicolumn{5}{|c|}{ PRESUPUESTO TOTAL } & $\$ \mathbf{4 4 9 , 9 9 2 . 7 6}$ \\
\hline
\end{tabular}

En el siguiente gráfico se puede apreciar el porcentaje del Share of Investment de cada medio sobre el presupuesto total. 


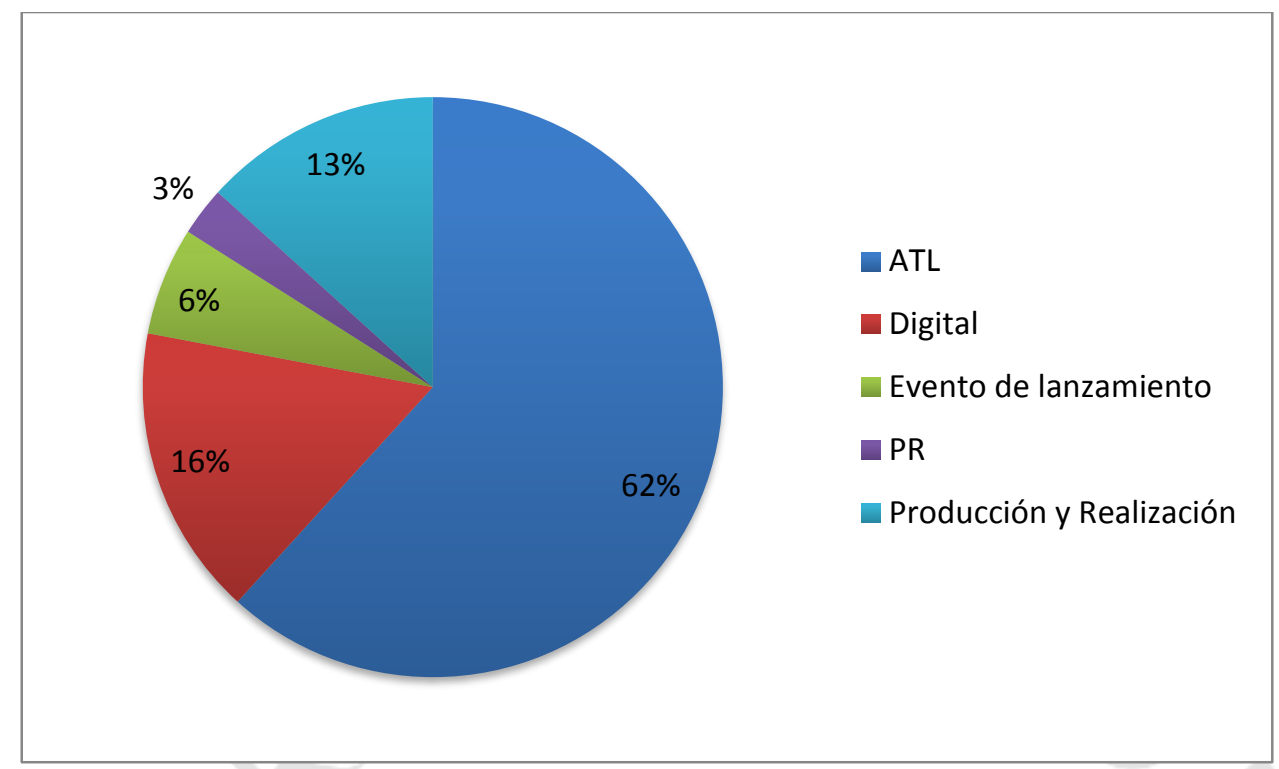

\subsubsection{ATL}

\section{$\underline{\mathrm{OOH}}$}

Según Ipsos, el joven adulto al ver un anuncio en la calle o centros comerciales, tiene un $42 \%$ de motivación de compra y, de ellos, el $80 \%$ llega a comprar el producto. Para la campaña de intriga se comprará pantallas digitales en vía pública por 1 hora por 1 semana para aprovechar las horas punta en Lima Metropolitana y causar gran impacto e intriga. Esto es para promover el evento, el objetivo es recaudar la mayor posibilidad de registros en la página del landingpage (www.efectoplacebo.com). Es decir, los mensajes en estas pantallas (que normalmente duran 7 segundos, tiempo aproximando para que la persona preste atención) serán relacionados con el efecto placebo para luego llevarlos a al landing para completar los datos de registro (ver PDF adjunto - Propuesta Pantalla Digital).

Una vez terminada la campaña de intriga, se pasará a comprar vallas publicitarias en 25 ubicaciones diferentes en distritos como Miraflores, San Isidro, San Borja, Surco, La Molina, Jesus María, Lince, Pueblo Libre y San Miguel, los cuales son los más favorecidos (NSE AB) según un estudio de la APEIM; así como también pantallas digitales dentro de los centros comerciales que el target normalmente visita como Jockey Plaza, La Rambla, Larcomar y Molina Plaza.

\section{$\underline{\text { TV }}$}

En cuanto a televisón abierta, se descargó el ranking de la plataforma TV Data y salió como resultado que los programas con mayor afinidad del público objetivo en cuestión 
son los que dan los sábados y domingos en las mañanas y aún así no se llegaban a los TGRPs suficientes, por lo que al final no se decidió usar televisión abierta. Sin embargo, también se descargó el ranking de televisión por cable y los programas más afines eran series o películas en horario prime de noche en canales como Fox, TNT, TBS, etc. Se llegarían a 231.60 TGRPs en un promedio de 1 mes y medio, lo cual es una buena opción para llegar a más alcance. En estos programas y en ese tiempo se pasaría el spot de TV de 30 segundos que se explicó anteriormente.

\section{$\underline{\text { Radio }}$}

Solo se utilizaría radio para la etapa de intriga; es decir, por 2 semanas. Se descargó el ranking en la plataforma de CPI y las emisoras con más afinidad hacia el target fueron Studio 92, Oxígeno y Moda.

Aparte de la cuña radial, se pueden hacer menciones en Studio 92 (top del ranking) sobre el efecto placebo en la cultura popular para que se vuelva tendencia con la ayuda de los hashtags en redes sociales, puesto que esta radio es la que más se mueve en plataformas como Twitter. Por ejemplo, que un locutor empiece poniendo “\#MiEfectoPlaceboEs echarme talco en la panza para que me pase el dolor” y que los seguidores continúen con su propia experiencia "\#MiEfectoPlaceboEs escuchar Lady Gaga para pasar un nivel". Al final del programa de la mención pueden decir "para más información entra a www.efectoplacebo.com para enterarte de más”.

\section{$\underline{\text { Prensa }}$}

Se eligió Publimetro como único diario puesto que es el más afín con el público objetivo. Se piensa realizar un cubreportada interno (mitad del diario) para que salga el lunes siguiente a la fecha de lanzamiento. Al tener 4 caras completas para llenar, se piensa dividirlo en aviso con el packaging, una nota de prensa sobre el evento que se realizó y los puntos de venta donde se encuentra el producto.

Además, se piensa llamar a la revista COSAS para que cubra el evento de lanzamiento para luego salir en la parte de Sociales el día de la siguiente edición de la revista.

\subsubsection{Medios Digitales}

Se busca aprovechar los medios POE (Paid, Owned, Earned):

-Los medios propios tienen un mejor contenido. Se pueden ir midiendo los resultados a través de Google Analytics. Para esto tendríamos la landingpage 
Www.efectoplacebo.com para la página de registro de la etapa de intriga. Esto sirve también para tener una base de datos que sirva a largo plazo. Además, la página web de la marca para el lanzamiento (www.schweller.com), la cual a diferencia de su competencia, esta sí tendría contenido en español. Finalmente, tener presencia en redes sociales como Facebook, Instagram y Twitter, según Ipsos, 1 de cada 10 usuarios de redes sociales afirma seguir marcas y la cuarta parte afirma que una marca ha influenciado su compra de alguna manera.

-Los medios ganados tienen mayor credibilidad. Se pueden medir los resultados con el alcance orgánico que ha tenido como comentarios, likes, RT's, shares, etc.

-Los medios pagados son más medibles. Se trabaja con el “embudo digital”: inversión, impresiones, clics, acciones. Los números se van achicando conforme se va llegando a las acciones y son ellos los posibles consumidores. En la inversión digital se propone los siguientes medios:

- Masthead en YouTube para el día de lanzamiento. Estar todo el día 20 de octubre en la página principal de esta plataforma con un banner en la cabecera y el spot de 30 segundos.

- Video instream: todos los días, el primer mes después de lanzado el producto. Son los videos de 5 segundos en YouTube antes de empezar el video que el usuario eligió. Este último, al poder poner skip al anuncio, se está pagando al costo por view completo; es decir, que el usuario haya visto todo el spot cuenta recién como 1 vista y eso es la que se paga.

- Spotify audio y video sponsored session: según Ipsos, poco más de 1/3 de los radio oyentes limeños escuchan música por stream, siendo la mayoría la audiencia a la que se quiere llegar.

- Google Display: se utilizará para el último mes de la campaña de lanzamiento como recordación de marca en los usuarios. Los más comunes son los banners cuadrados a los lados que aparecen en las páginas con los intereses de la audiencia.

- Facebook: da a conocer la marca, promociona, aumenta ventas y genera engagement. Se promocionarían posts del fanpage de Schweller y la misma fanpage en sí. 
- Instagram: el clic to website en los stories en la etapa de intriga para llegar a los registros requeridos para el evento de lanzamiento. El page post engagement se haría después del evento para tener más awareness.

- Twitter: microblogging para lograr un mayor engagement aprovechando las tendencias con el uso de los hashtags. Instant unlock card es un clic to action para captar la atención del usuario con contenidos exclusivos que se desbloquean a cambio de un tweet para ver el contenido.

- Rich Media: finalmente, se utilizaría esta modalidad para la última semana de la campaña. Son videos con interacción en aplicaciones de juegos para que el usuario interactúe y finalmente lo llevé a un link para realizar una acción.

\subsubsection{Relaciones Públicas}

De lo que se propone invertir en PR un monto va para la etapa de intriga para contratar a influencers y líderes de opinión para este target. Según Ipsos, el 20\% del target sigue a influencers. Esto va más que nada para un público más joven y los influencers pueden ayudar a promocionar el evento de lanzamiento. El otro monto sirve para publirreportajes, y comunicación de marca, lo cual ayuda en la construcción de la marca en un largo plazo.

\subsubsection{Evento de lanzamiento}

Como ya se ha ido explicando, se realizará un evento de lanzamiento el día 19 de octubre, donde participarán influencers, líderes de opinión y el mismo target, quienes luego se convertirán en posibles consumidores. Este evento es importante para el lanzamiento porque la marca va a pasar del desconocimiento al conocimiento entre el público objetivo, lo cual provocará que se hable del producto y lo que más cuenta es la comunicación de word of mouth porque le da más credibilidad y confianza al producto. Todo el evento será cubierto en video y fotos para luego publicarlas en las redes sociales y que la gente lo comparta para lograr más awareness. Se hará una gran inversión porque tiene que incluir la música, las luces, la animación, el alquiler del local y el servicio. 


\section{RESULTADOS ESPERADOS}

Al ser una campaña de 3 meses, se quiere llegar al 60\% de awareness de la marca por parte del target.

Buscar incrementar la cantidad y calidad de tráfico que se logra a través de los resultados orgánicos en motores de búsqueda.

Comunicación viral: que la audiencia difundan el producto de manera espontánea.

Posicionamiento de marca como la cerveza sin alcohol para disfrutar sin preocupaciones.

Ser relevantes para seguir comunicando en la etapa de mantenimiento de la marca.

Utilizar email marketing para la base de datos recolectada a lo largo de la campaña de lanzamiento para enviarles futuras promociones.

Tener negociaciones futuras con bares o discotecas para distribuir el producto en sus locales. 


\section{REFERENCIAS}

\section{Bibliografía}

APEIM. (2005). APEIM. Obtenido de NIVELES SOCIOECONÓMICOS EN LIMA METROPOLITANA Y CALLAO: http://www.apeim.com.pe/wpcontent/themes/apeim/docs/nse/APEIM-NSE-2003-2004-LIMA.pdf

Banco Central de Reserva. (2017).

Bitburger. (s.f.). Bitburger. Obtenido de https://www.bitburger.de/aktiv-alkoholfrei00/uebersicht/

Erdinger Alkoholfrei. (s.f.). Erdinger Weissbräu. Obtenido de https://int.erdinger.de/beer/alkoholfrei.html

Euromonitor. (2018). Euromonitor International. Obtenido de www.euromonitor.com/beer-in-peru/report

INEI. (s.f.). Instituto Nacional de Estadística e Informática. Obtenido de INEI: www.inei.gob.pe

IPSOS. (2018). Perfil del adulto joven.

IPSOS. (2018). Perfil del usuario de redes sociales.

Kantar IBOPE Media . (2017). Target Group Index (TGI).

Kantar IBOPE Media. (s.f.). Monitor Multimedios. Perú.

Mercado Negro, M. (2014). Mercado Negro. Obtenido de Mercado Negro: http://www.mercadonegro.pe/marcas-que-fracasaron-en-peru/

Ministerio de Transportes y Comunicaciones. (s.f.). SUTRAN. Obtenido de http://www.sutran.gob.pe/wp-content/uploads/2017/05/BASE-DATOS-TABLASREGLAMENTOS_revfinalRETRAN.pdf

The Top 10.000 Companies ,. (2018). The Top 10.000 Companies 2017 Perú. 


\section{ANEXOS}

\section{ANEXO 1: RESULTADOS ENCUESTA}

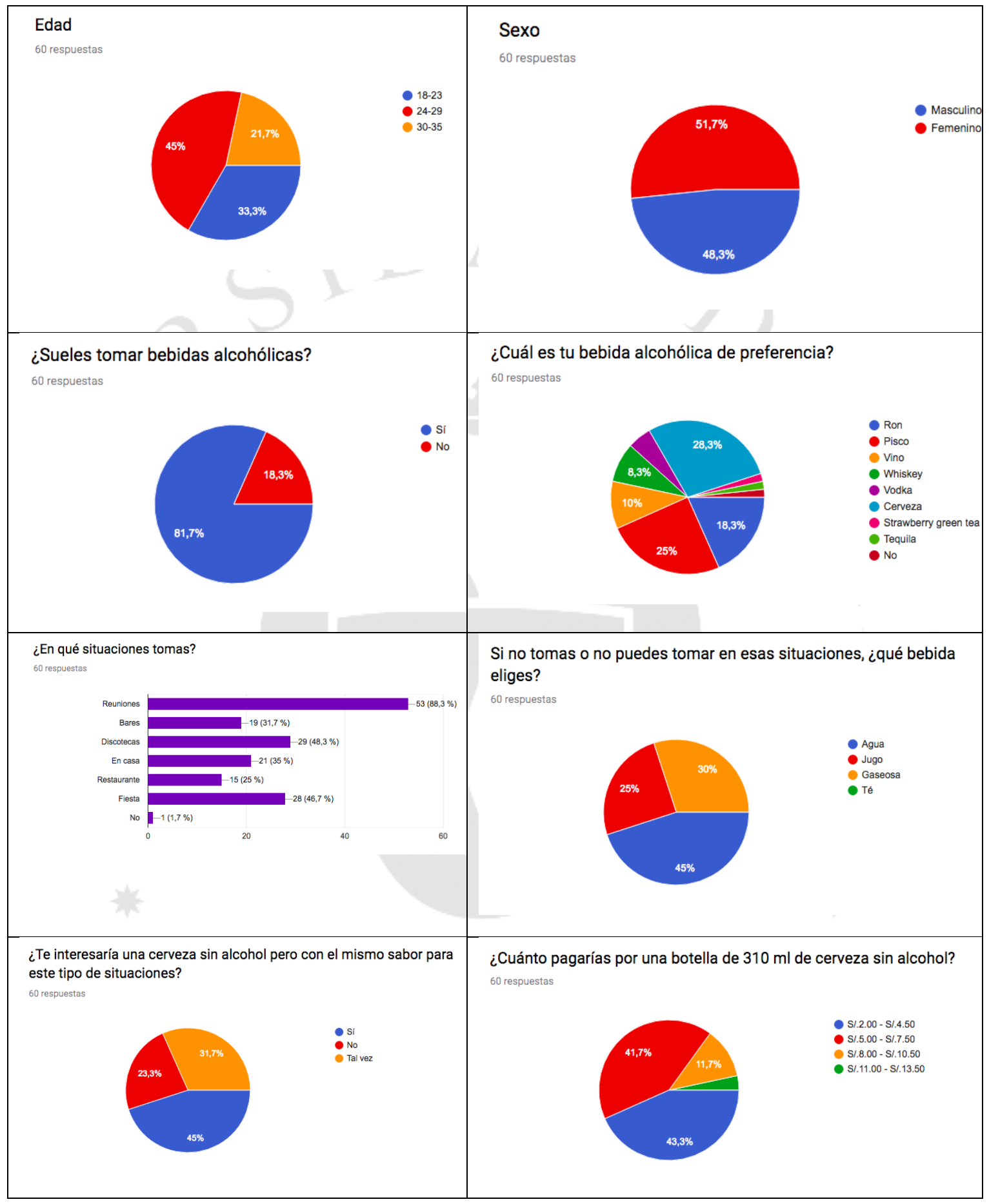




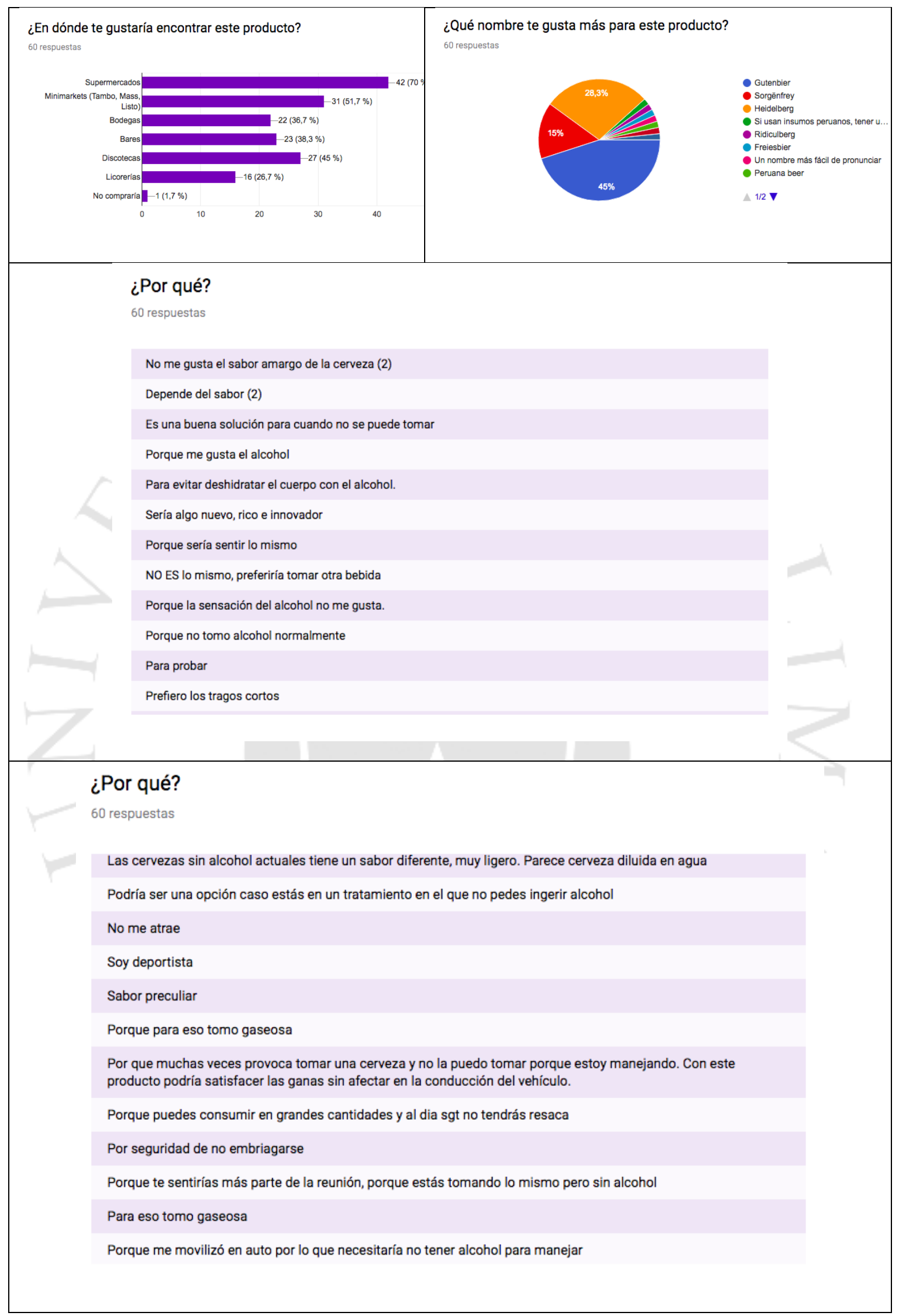




\section{¿Por qué?}

\section{0 respuestas}

por acompañar en las reuniones

Prefiero bebidas dulces o agua

no es el mismo sabor

Seria interesante probar nuevas bebidas y que no hagan daño a la salud

Para pensar que estoy tomando lo mismo

No frecuento en tomar cerveza

Porque me gusta la cerveza y el alcohol no es bueno para la salud.

Es otro feeling que simplemente algo cotidiano, pero sin alcohol y mas sano

Porque el grado de alcohol no afectaría a los órganos del cuerpo

Es más saludable

Puede ayudar a amenizar la reunión sin la nesecidad de que la personas se lleguen a embriagar

Por curosiodad

\section{¿Por qué?}

60 respuestas

Para poder manejar

Tendria que probar y ver como es o a que sabe porque siendo sonceros no seria igual claro tendria un parecido pero igual no seria

Ayudaría mucho en caso de situaciones de que la reunión sea en día de semana.

Algo nuevo

No me gusta la cebada

Nuevo producto

La cerveza no es una bebida de mis favoritas, sin embargo considero que seria una alternativa mas agradable para una reunión especial

Porque no me gusta la cervezs

Por un tema de salud

Sería otra opción

Porque me gusta asistir a diferentes reuniones mas no tomar bebidas alcoholicas y seria ideal poder brindar toda el tiempo que dure la reunion con bebidas sin alcohol 


\begin{tabular}{|c|}
\hline $\begin{array}{l}\text { ¿Por qué? } \\
60 \text { respuestas }\end{array}$ \\
\hline Porque el alcohol le da ese sabor caracteristico de todas las cervezas \\
\hline Para hacer la "finta" de estar tomando sin embriagarse \\
\hline Para no emborracharme \\
\hline La finalidad de la cerveza es tomar algo de alcohol para amenizar las reuniones \\
\hline Para no marear se \\
\hline $\begin{array}{l}\text { Porque preferiría tomar agua para tal caso, la gracia de uña cervezas no necesariamente es su sabor en realidad a } \\
\text { nadie creo yo que le agrada el sabor, lo beben porque como toda bebida con alchol altera de diferente formas en } \\
\text { las personas (euforia, alegria, etc) }\end{array}$ \\
\hline Siempre y cuando no me hinche la barriga como la cervez \\
\hline Una opción para cuando no desee tomar en una reunion y asi poder compartir sin necesidad de embriagarse \\
\hline $\begin{array}{l}\text { Es una muy buena alternativa, tienes absolutamente el mismo sabor ( por lo tanto sensación ), acompañas a tus } \\
\text { amigos en la reunión sin decir que no tomas y no te hace daño( por el motivo que sea: salud, pastillas, mala } \\
\text { cabeza,etc) }\end{array}$ \\
\hline Tendría que probarlo una vez \\
\hline I a cerveza pe refrescante \\
\hline 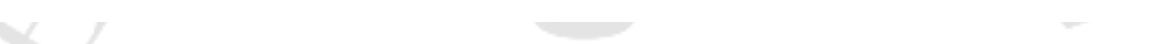 \\
\hline
\end{tabular}

\section{ANEXO 2: KANTAR IBOPE TGI 2017}

TGI Peru 2018 Ola I (Y19w1) v.04.23.2018 - Personas

Copyright TGI LATINA 2017

Base: Muestra Total

\begin{tabular}{|c|c|c|c|}
\hline & 18 a $35 \mathrm{AB}[1]$ & $\begin{array}{c}18 \text { a } 35 \mathrm{AB} \\
\text { consumidores } \\
\text { cerveza[1] }\end{array}$ & $\begin{array}{c}18 \text { a } 35 \mathrm{AB} \text { no } \\
\text { consumidores } \\
\text { cerveza[1] }\end{array}$ \\
\hline Muestra Total & $100 \%$ & $100 \%$ & $100 \%$ \\
\hline Consumidas - U7d:Backus Ice & $0.00 \%$ & $0.00 \%$ & $0.00 \%$ \\
\hline Consumidas - U7d:Brahma & $0.00 \%$ & $0.00 \%$ & $0.00 \%$ \\
\hline Consumidas - U7d: Budweiser & $0.00 \%$ & $0.00 \%$ & $0.00 \%$ \\
\hline Consumidas - U7d: Corona & $9 \%$ & $14 \%$ & $0.00 \%$ \\
\hline Consumidas - U7d: Cristal & $8 \%$ & $13 \%$ & $0.00 \%$ \\
\hline Consumidas - U7d: Cusqueña & $16 \%$ & $24 \%$ & $0.00 \%$ \\
\hline Consumidas - U7d: Heineken & $3 \%$ & $4 \%$ & $0.00 \%$ \\
\hline Consumidas - U7d: Lowenbrau & $0.00 \%$ & $0.00 \%$ & $0.00 \%$ \\
\hline Consumidas - U7d: Cusqueña Malta & $3 \%$ & $5 \%$ & $0.00 \%$ \\
\hline Consumidas - U7d: Miller & $0.80 \%$ & $1 \%$ & $0.00 \%$ \\
\hline Consumidas - U7d: Pilsen Callao & $30 \%$ & $47 \%$ & $0.00 \%$ \\
\hline Consumidas - U7d: Pilsen Trujillo & $0.00 \%$ & $0.00 \%$ & $0.00 \%$ \\
\hline Consumidas - U7d: Stella Artois & $0.36 \%$ & $0.55 \%$ & $0.00 \%$ \\
\hline Consumidas - U7d: Otra marca & $1 \%$ & $2 \%$ & $0.00 \%$ \\
\hline
\end{tabular}




\begin{tabular}{|c|c|c|c|}
\hline & 18 a $35 \mathrm{AB}[1]$ & $\begin{array}{c}18 \text { a } 35 \mathrm{AB} \\
\text { consumidores } \\
\text { cerveza[1] }\end{array}$ & $\begin{array}{c}18 \text { a } 35 \text { AB no } \\
\text { consumidores } \\
\text { cerveza[1] }\end{array}$ \\
\hline Muestra Total & $100 \%$ & $100 \%$ & $100 \%$ \\
\hline Grupo superior/de acuerdo (2): Me parece que la publicidad en TV es interesante y ofrece algo de que hablar & $42 \%$ & $46 \%$ & $35 \%$ \\
\hline Grupo superior/de acuerdo (2): Las revistas son mi principal fuente de entretenimiento & $17 \%$ & $16 \%$ & $18 \%$ \\
\hline Grupo superior/de acuerdo (2): La publicidad influye en mis decisiones de compra & $41 \%$ & $41 \%$ & $39 \%$ \\
\hline Grupo superior/de acuerdo (2): La televisión es mi principal fuente de entretenimiento & $40 \%$ & $39 \%$ & $42 \%$ \\
\hline Grupo superior/de acuerdo (2): Casi toda la publicidad en televisión me molesta & $27 \%$ & $27 \%$ & $26 \%$ \\
\hline Grupo superior/de acuerdo (2): La radio es mi principal fuente de entretenimiento & $30 \%$ & $32 \%$ & $27 \%$ \\
\hline Grupo superior/de acuerdo (2): Me gusta leer la publicidad en las revistas & $27 \%$ & $28 \%$ & $25 \%$ \\
\hline Grupo superior/de acuerdo (2):La publicidad me parece una pérdida de tiempo & $24 \%$ & $24 \%$ & $24 \%$ \\
\hline Grupo superior/de acuerdo (2):Voy al cine con regularidad & $38 \%$ & $43 \%$ & $30 \%$ \\
\hline Grupo superior/de acuerdo (2):Cuando necesito información, el primer lugar donde busco es en el Internet & $66 \%$ & $67 \%$ & $64 \%$ \\
\hline Grupo superior/de acuerdo (2): Internet es mi principal fuente de entretenimiento & $57 \%$ & $60 \%$ & $53 \%$ \\
\hline upo superior/de acuerdo (2):Frecuentemente uso las redes sociales para enviar y/o recibir comentarios entre amig & $57 \%$ & $59 \%$ & $53 \%$ \\
\hline Grupo superior/de acuerdo (2): Me interesaría recibir publicidad en mi teléfono celular o Smartphone & $31 \%$ & $32 \%$ & $28 \%$ \\
\hline Grupo superior/de acuerdo (2): Suelo ser influenciado por comentarios y/u opiniones posteadas online & $23 \%$ & $21 \%$ & $26 \%$ \\
\hline irupo superior/de acuerdo (2): Mientras veo TV, hago búsquedas en el Internet sobre productos que veo anunciado & $33 \%$ & $32 \%$ & $34 \%$ \\
\hline
\end{tabular}

\section{TGI Peru 2018 Ola I (Y19w1) v.04.23.2018 - Personas}

\section{Copyright TGI LATINA 2017}

\section{Base: Muestra Total}

\begin{tabular}{|c|r|r|r|}
\hline & & & \\
\hline & 18 a $35 \mathrm{AB}[1]$ & $\begin{array}{c}18 \text { a } 35 \mathrm{AB} \\
\text { consumidores } \\
\text { cerveza[1] }\end{array}$ & $\begin{array}{c}18 \text { a } 35 \text { AB no } \\
\text { consumidores } \\
\text { cerveza[1] }\end{array}$ \\
\hline Muestra Total & $100 \%$ & $100 \%$ & $100 \%$ \\
\hline Cerveza / Frecuentemente: Botella[1] & $23 \%$ & $36 \%$ & $0.00 \%$ \\
\hline Cerveza / Frecuentemente: Lata[1] & $11 \%$ & $17 \%$ & $0.00 \%$ \\
\hline Cerveza / Frecuentemente: Barril/ chopp[1] & $1 \%$ & $2 \%$ & $0.00 \%$ \\
\hline Cerveza / Frecuentemente: Negra[1] & $3 \%$ & $5 \%$ & $0.00 \%$ \\
\hline Cerveza / Frecuentemente: Sin Alcohol[1] & $23 \%$ & $37 \%$ & $0.00 \%$ \\
\hline Cerveza / Niveles de Consumo: Consumidores altos[1] & $\mathbf{0 . 0 0 \%}$ & $\mathbf{0 . 0 0 \%}$ & $\mathbf{0 . 0 0 \%}$ \\
\hline Cerveza / Niveles de Consumo: Consumidores medios[1] & $7 \%$ & $11 \%$ & $0.00 \%$ \\
\hline Cerveza / Niveles de Consumo: 1-6 vasos - U7d[1] & $17 \%$ & $27 \%$ & $0.00 \%$ \\
\hline
\end{tabular}

TGI Peru 2018 Ola I(Y19w1) v.04.23.2018 - Personas

Copyright TGI LATINA 2017

Base: Muestra Total

\begin{tabular}{|c|c|c|c|}
\hline & 18 a $35 \mathrm{AB}[1]$ & $\begin{array}{c}18 \text { a } 35 \mathrm{AB} \\
\text { consumidores } \\
\text { cerveza[1] }\end{array}$ & $\begin{array}{c}18 \text { a } 35 \mathrm{AB} \text { no } \\
\text { consumidores } \\
\text { cerveza[1] }\end{array}$ \\
\hline Muestra Total & $100 \%$ & $100 \%$ & $100 \%$ \\
\hline Grupo superior/de acuerdo (2):Me gusta tomar riesgos & $63 \%$ & $68 \%$ & $54 \%$ \\
\hline Grupo superior/de acuerdo (2):Prefiero pasar una noche tranquila en casa, en lugar de salir & $61 \%$ & $57 \%$ & $69 \%$ \\
\hline Grupo superior/de acuerdo (2): Disfruto recibiendo gente en mi casa & $45 \%$ & $42 \%$ & $51 \%$ \\
\hline Grupo superior/de acuerdo (2): Me preocupo mucho sobre mí mismo & $55 \%$ & $58 \%$ & $48 \%$ \\
\hline Grupo superior/de acuerdo (2): Fácilmente me dejo influenciar por otras personas & $25 \%$ & $22 \%$ & $29 \%$ \\
\hline po superior/de acuerdo (2): Siempre prefiero a aquellas empresas que se comprometen a combatir las desigualdades soci & $58 \%$ & $61 \%$ & $52 \%$ \\
\hline Grupo superior/de acuerdo (2): Me gusta probar nuevos productos alimenticios & $47 \%$ & $50 \%$ & $42 \%$ \\
\hline Grupo superior/de acuerdo (2): Casi siempre vale la pena pagar más por productos de calidad & $66 \%$ & $71 \%$ & $57 \%$ \\
\hline Grupo superior/de acuerdo (2): Hoy en día, hay mucho patrocinio en las artes y los deportes & $58 \%$ & $62 \%$ & $50 \%$ \\
\hline Grupo superior/de acuerdo (2): Me interesa saber sobre otras culturas & $64 \%$ & $64 \%$ & $62 \%$ \\
\hline Grupo superior/de acuerdo (2):No me gusta juzgar a otros por lo que hacen en su vida & $57 \%$ & $59 \%$ & $55 \%$ \\
\hline Grupo superior/de acuerdo (2): Prefiero productos de empresas que apoyan proyectos sociales o culturales & $50 \%$ & $51 \%$ & $47 \%$ \\
\hline Grupo superior/de acuerdo (2):La razón de tomar alcohol es emborracharse & $24 \%$ & $25 \%$ & $23 \%$ \\
\hline Grupo superior/de acuerdo (2):Es importante estar atractivo para el sexo opuesto & $54 \%$ & $52 \%$ & $57 \%$ \\
\hline Grupo superior/de acuerdo (2): Me gusta probar nuevos tragos y bebidas & $42 \%$ & $50 \%$ & $26 \%$ \\
\hline Grupo superior/de acuerdo (2): Mi carro sólo está ahí para llevarme de un sitio a otro & $39 \%$ & $43 \%$ & $31 \%$ \\
\hline Grupo superior/de acuerdo (2):Me gusta manejar & $40 \%$ & $42 \%$ & $36 \%$ \\
\hline
\end{tabular}


ANEXO 3: PRESUPUESTO REALIZACIÓN

\begin{tabular}{|c|c|c|c|}
\hline $\begin{array}{l}\text { Cant } \\
\text { dad }\end{array}$ & Realización & Costo $\mathrm{x}$ unidad & Presupuesto \\
\hline 1 & Cámara Red One & $2,500.00$ & $\$ 2,500.00$ \\
\hline 1 & Dolly & 300.00 & 300.00 \\
\hline 1 & Steadycam & $1,000.00$ & S $1,000.00$ \\
\hline 4 & Chroma green screen & 250.00 & \$ $1,000.00$ \\
\hline 2 & HMI $1200 \mathrm{w}$ & 100.00 & 200.00 \\
\hline 4 & Fresnel 150 & 25.00 & 100.00 \\
\hline 4 & Fresnel 300 & 35.00 & 140.00 \\
\hline 2 & Fresnel 650 & 40.00 & 80.00 \\
\hline 2 & Fresnel 1000 & 45.00 & 90.00 \\
\hline 2 & Fresnel 2000 & 60.00 & 120.00 \\
\hline 2 & Kino & 30.00 & 60.00 \\
\hline 2 & Tripode & 45.00 & 90.00 \\
\hline 2 & Camión & 250.00 & 500.00 \\
\hline 2 & Filtros & 150.00 & 300.00 \\
\hline & Edición offline & $1,000.00$ & \$ $1,000.00$ \\
\hline & Edición final & 800.00 & 800.00 \\
\hline 8 & Copias & 40.00 & 320.00 \\
\hline & Animación & $2,000.00$ & \$ $2,000.00$ \\
\hline & Animatic & $\begin{array}{|ll|}5 & 1,000.00 \\
\end{array}$ & \$ $1,000.00$ \\
\hline \multicolumn{3}{|c|}{ SUBTOTAL 1} & $\$ 11,600.00$ \\
\hline & Imprevistos & & \$ $1,160.00$ \\
\hline & Director & & \$ $4,500.00$ \\
\hline & Director de Fotografia & & $\$ 4,500.00$ \\
\hline & Camarógrafo & & $\$ 2,000.00$ \\
\hline & Jefe de luz & & \$ $2,100.00$ \\
\hline & Asistente de luz & & 800.00 \\
\hline & Electricista & & 600.00 \\
\hline & Asistente de rodaje & & 300.00 \\
\hline & Asistente de dirección & & $\$ 2,000.00$ \\
\hline & Script & & 600.00 \\
\hline & Asistente de cámara 1 & & \$ $1,550.00$ \\
\hline & Asistente de cámara 2 & & 900.00 \\
\hline & Actriz & & \$ $1,500.00$ \\
\hline & Actor & & S $1,500.00$ \\
\hline 20 & Extras & 150.00 & \$ $3,000.00$ \\
\hline \multicolumn{3}{|c|}{ SUBTOTAL 2} & $\$ 32,610.00$ \\
\hline & Empresa realizadora & $30 \%$ & S $9,783.00$ \\
\hline & Impuesto a la renta & $5 \%$ & $\begin{array}{ll}\$ & 1,630.50 \\
\end{array}$ \\
\hline \multicolumn{3}{|c|}{ SUBTOTAL 3} & $544,023.50$ \\
\hline & Agencia & $15 \%$ & S $6,603.53$ \\
\hline \multicolumn{3}{|c|}{ TOTAL } & $\$ 50,627.03$ \\
\hline & $16 \mathrm{~V}$ & $18 \%$ & \$ $9,112.86$ \\
\hline \multicolumn{3}{|c|}{ TOTAL + IGV } & $\$ 59,739.89$ \\
\hline
\end{tabular}




\section{ANEXO 4: CRONOGRAMA}

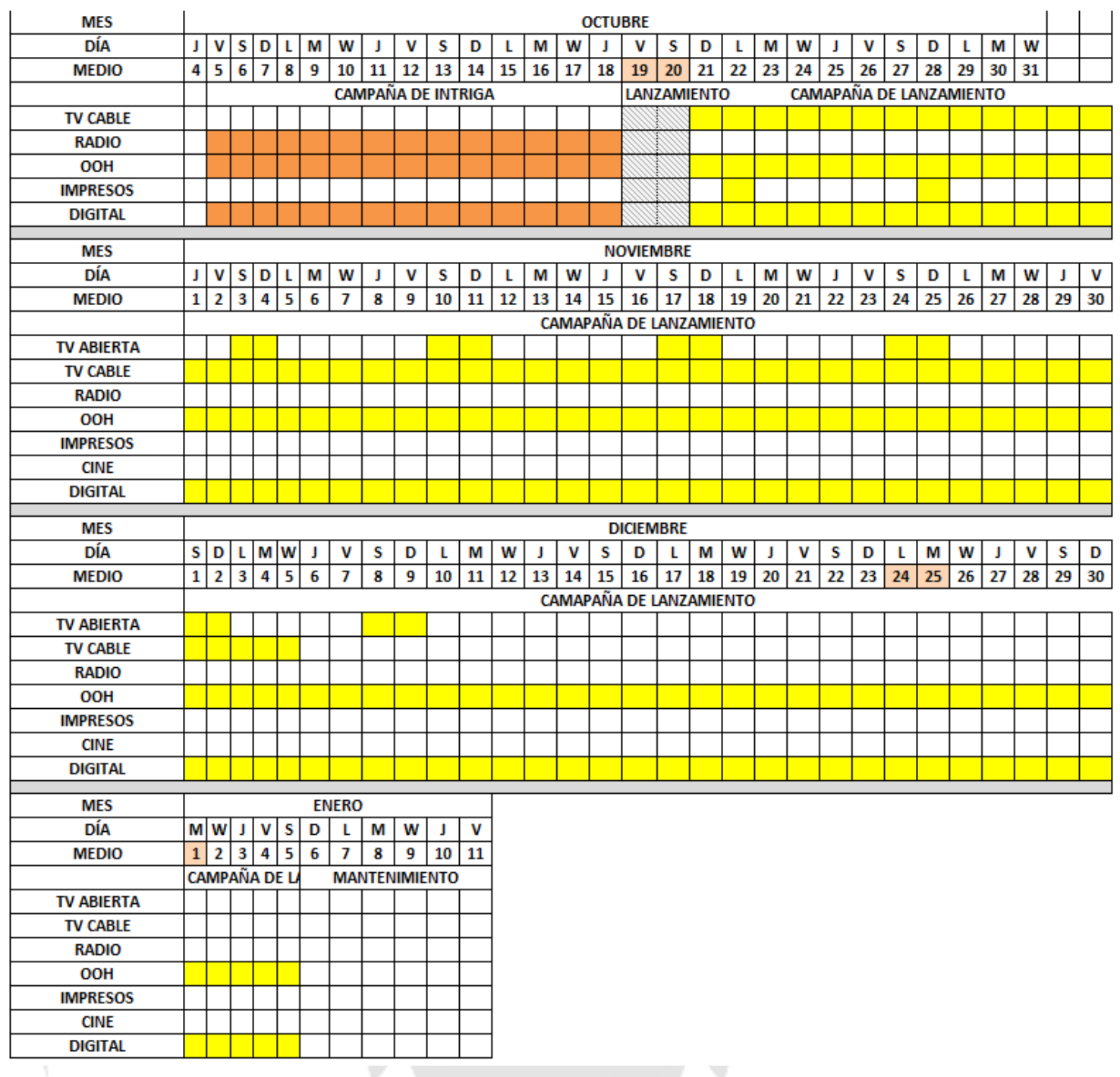

